\title{
Od luk w wiedzy do wniosku o istnieniu Boga *
}

Argumenty z projektu na rzecz istnienia Boga często wyszczególniaja jakiś aspekt świata przyrody, którego nie można wyjaśnić w świetle naszej aktualnej wiedzy o prawach natury. Taka lukę w wiedzy interpretuje się jako świadectwo istnienia bytu nadnaturalnego. ${ }^{1}$ Krytycy opisanego podejścia szufladkuja owe argumenty jako błędne koncepcje „Boga w lukach wiedzy”, dlatego że ostabiaja one poparcie dla tezy o Bogu Stwórcy, w miare jak luki te znikaja wraz ze wzrostem wiedzy. ${ }^{2}$ Wielu ludzi odrzuca argumenty $z$ projektu na rzecz istnienia Boga, ponieważ sa przeświadczeni, że pewnego dnia nauka wypetni wszystkie takie luki. Jednakże luki w wiedzy o przyrodzie rzeczywiście występuja $i$ społeczność naukowa przyznaje, że wielu $z$ nich nie da się usunać, nawet $w$ zasadzie. Niniejszy artykut dokonuje przegladu różnorodnych rodzajów luk i rozważa ich rolę w argumentacji na rzecz Boga.

\footnotetext{
* Randy Isaac, ,From Gaps to God”, Perspectives on Science and Christian Faith 2005, vol. 57, no. 3, s. 230-233, http://www.asa3.org/ASA/PSCF/2005/PSCF9-05Isaac.pdf (16.11.2012). Za zgodą Redakcji z języka angielskiego przełożyła: Małgorzata GAzDA.

${ }^{1} \mathrm{~W}$ sprawie wczesnej historii argumentów z projektu por. Richard THORnHILl, „Historyczny związek między darwinizmem a argumentem z biologicznego projektu”, przeł. Anna Droś, Natalia Górska, Mateusz Krzyżanowski, Renata Merda, Zofia Sadowska i Dariusz Sagan, Filozoficzne Aspekty Genezy 2012, t. 9, s. 79-106, http://www.nauka-a-religia.uz.zgora.pl/index.phpaction=tek st\&id=233 (16.11.2012).

${ }^{2}$ Por. David F. SiEmens, Jr., „On Moreland: Spurious Freedom, Mangled Science, Muddled Philosophy”, Perspectives on Science and Christian Faith 1997, vol. 49, s. 196-199.
} 
W tym artykule zajmiemy się jedynie wiedzą naturalistyczną, pomijając duchową czy objawiona nie dlatego, że ta ostatnia nie jest prawdziwa lub istotna, lecz dlatego, że chcemy zbadać, czy w ograniczeniach naturalistycznego poznania może ujawniać się istnienie rzeczywistości nadprzyrodzonej. Możemy uznać, że całą możliwą naturalistyczną wiedzę da się podzielić na dwa główne podzbiory: to, co wiemy, $W$, oraz to, czego nie wiemy, $N$.

W zbiorze $N$ można następnie wyróżnić kolejne dwa podzbiory. Pierwszy, oznaczony jako $N_{p}$, stanowi to, czego nie wiemy, ale co możemy poznać - nieznane, ale poznawalne. Punktem wyjściowym badań naukowych jest wskazanie obszaru zainteresowania w zbiorze $N_{p}$. Udane badania przynoszą nową wiedzę, która po sprawdzeniu przez innych uczonych i wykazaniu, że zjawiska, o jakich ona mówi, są powtarzalne, zostaje zaakceptowana przez społeczność naukową jako element zbioru $W$. Najlepsze projekty badawcze skutkują także rozpoznaniem innych istotnych obszarów w zbiorze $N_{p}$. Drugi zbiór, $N_{n}$, obejmuje to, o czym wiemy, że nie zostało poznane, i co jest niepoznawalne w ramach naturalizmu metodologicznego.

Spory wokół argumentów typu „Bóg w lukach wiedzy” zazwyczaj koncentrują się na próbie ustalenia, czy dany element należy do zbioru $N_{n}$ czy $N_{p}$. Argument na rzecz istnienia Boga oparty na twierdzeniu, że wyjaśnienie pewnego zjawiska znajduje się w zbiorze $N_{n}$, często odpiera się tezą przeciwną, mianowicie że w istocie znajduje się ono w zbiorze $N_{p}$ i w końcu trafi do zbioru $W$. Zanim dany element stanie się częścią zbioru $W$, nie zawsze można łatwo określić, czy należy on do zbioru $N_{n}$ czy $N_{p}$.

Społeczność naukowa przyznaje, że $N_{n}$ nie jest zbiorem pustym. Niniejszy artykuł omawia sześć rodzajów luk w wiedzy i rozważa ich implikacje.

\section{Statystyka}

Do pierwszej kategorii należą przedmioty badań złożone z olbrzymiej liczby elementów, a przez to poznawalne tylko na podstawie danych statystycznych. Liczba Avogadro, $6 \times 10^{23}$, czyli liczba atomów bądź cząsteczek obecnych w molu substancji, jest tak niewyobrażalnie wielka, że nie da się określić własności każdej cząsteczki nawet w niewielkiej, ale makroskopowej ilości substan- 
cji. Niemniej statystyczne metody i rozkłady, jak rozkłady Gaussa i Boltzmanna, pozwalają określać cechy, takie jak ciśnienie, temperatura, prędkość i tak dalej.

Z punktu widzenia mechaniki klasycznej indywidualne własności każdej cząsteczki są w zasadzie poznawalne, przez co można ten przykład zaliczyć raczej do zbioru $N_{p}$ niż $N_{n}$. Jednakże w praktyce nigdy nie zostaną poznane. Praktyczna niepoznawalność, w przeciwieństwie do niepoznawalności zasadniczej, wynika zazwyczaj z ograniczeń narzędzi, jakimi dysponujemy. Możliwość gromadzenia i operowania ogromną ilością danych przy użyciu dostępnych komputerów sprawiła, że zdobycie wiedzy dotychczas uważanej za nieosiągalną stało się realne. Niepoznawalność zasadnicza oznacza, że naszą wiedzę ograniczają nie narzędzia, lecz podstawowe koncepcje. $\mathrm{W}$ tym przypadku posiadamy instrumenty umożliwiające mierzenie cech większego skupiska cząsteczek, ale nienadające się do prowadzenia podobnych pomiarów dla każdej pojedynczej cząsteczki obecnej w molu substancji.

\section{Chaos}

Drugi rodzaj luk dotyczy wpływu niezmiernie małych czynników na powstawanie efektów o większej skali. Teoria chaosu, pod którą podwaliny położył Edward Lorenz w latach sześćdziesiątych minionego wieku, ${ }^{3}$ głosi, że pewne warunki początkowe, których nie jesteśmy w stanie precyzyjnie mierzyć, mogą bardzo silnie wpływać na przebieg wielu codziennych zjawisk. ${ }^{*} \mathrm{~W}$ ujęciu fizyki klasycznej te ostatnie zjawiska pojawiają się przypadkowo, ale często można wykazać, że w rzeczywistości u ich podstaw leżą jakieś ukryte regularności. Wrażliwość układów nieliniowych na warunki początkowe zawsze będzie wyższa niż możliwości dokonywania ich pomiaru, mimo wzrostu precyzji pomiarowej. ${ }^{4}$ Ta część zbioru $N_{n}$ może się zatem kurczyć, jednak nigdy całkowicie nie zniknie.

\footnotetext{
${ }^{3}$ Por. Edward N. Lorenz, „Deterministic Nonperiodic Flow”, Journal of Atmospheric Science 1963, vol. 20, s. 130-141.

* (Przyp. tłum.) Na przykład trzepot skrzydeł motyla w Pekinie może wywołać burzę przechodzącą w następnym miesiącu nad Nowym Jorkiem.

${ }^{4}$ Por. James Gleick, Chaos. Narodziny nowej nauki, przeł. Piotr Jaśkowski, Wydawnictwo Zysk i S-ka, Poznań 1996. Jest to przystępnie napisana popularyzatorska książka o teorii chaosu.
} 


\section{Efekty kwantowe}

Wraz z nastaniem $\mathrm{w}$ latach dwudziestych minionego stulecia mechaniki kwantowej otworzyło się szerokie pole niepoznawalności. Było to sprzeczne z mechaniką Newtona, która głosiła ostateczną poznawalność wszelkiego ruchu. Cztery rodzaje niepoznawalności kwantowej warto prześledzić bardziej szczegółowo.

\section{A. Zasada nieoznaczoności}

Zasadę nieoznaczoności (lub zasadę nieokreśloności) sformułował w 1927 roku Heisenberg. ${ }^{5}$ Matematycznie rzecz ujmując, wyraża ona między innymi następujące dwie relacje:

$$
\begin{aligned}
& \Delta p \Delta q \geq h / 4 \pi \\
& \Delta E \Delta t \geq h / 4 \pi
\end{aligned}
$$

gdzie $p$ oznacza pęd, $q$ - położenie, $E$ - energię, $t$ - czas, a $h$ - stałą Plancka, wynoszącą $6,6 \times 10^{-34} \mathrm{~m}^{2} \mathrm{~kg} / \mathrm{s}$. Heisenberg uświadomił sobie doniosłe implikacje filozoficzne tych zależności. Skoro pęd i położenie nie mogą być jednocześnie znane z dowolną dokładnością, ${ }^{*}$ to do równań ruchu nie można podstawić dostatecznie dokładnych danych, aby śledzić zachowanie świata. Tym samym upadła wizja przewidywalnego i poznawalnego świata. Naukowcy uznają to wewnętrzne ograniczenie poznania od prawie osiemdziesięciu lat, można je więc bez cienia wątpliwości zaliczyć do zbioru $N_{n}$.

\footnotetext{
${ }^{5}$ Por. Werner Heisenberg, „Über den anschaulichen Inhalt der quantentheoretische Kinematik und Mechanik", w: Zeitschrift für Physik, Bd. 43, Julius Springer, Berlin 1927, s. 172-198.

* (Przyp. rec.) Jeśli operatory reprezentujące dane obserwable (wielkości fizyczne mierzalne) nie komutują ze sobą (są nieprzemienne), to jednoczesny pomiar tych wielkości z dowolną dokładnością jest niemożliwy (oprócz pędu i położenia dotyczy to także na przykład składowych spinu). Warto przy tym zauważyć osobliwy charakter zasady nieoznaczoności dla energii i czasu, ponieważ czas nie jest w mechanice kwantowej reprezentowany przez operator. Należy też dodać, że w wymienionych relacjach $\Delta$ nie oznacza „niepewności” (co może się kojarzyć z subiektywną niepewnością), lecz pierwiastek ze średniego odchylenia kwadratowego od wartości średniej, gdzie wartość średnia jest zdefiniowana jako wartość oczekiwana operatora.
} 


\section{B. Stany kwantowe}

W przeciwieństwie do mechaniki klasycznej, zgodnie z którą cząstki poruszają się w czasoprzestrzeni wzdłuż przewidywalnych trajektorii, mechanika kwantowa opisuje cząstki przy pomocy pojęcia amplitudy funkcji falowej, która podniesiona do kwadratu oznacza prawdopodobieństwo, z jakim cząstka posiada określoną własność. Możemy ustalić jedynie, ile wynosi prawdopodobieństwo, że dana cząstka posiada pewną konkretną wartość jakiejś cechy. ${ }^{*}$ Co więcej, zmierzony stan cząstki zależy od wykonanego pomiaru. Wiedza na temat cząstki jest zatem z natury statystyczna, chociaż w istotny sposób różni się od statystycznej wiedzy omówionej wyżej. Tutaj statystyczny aspekt jest nieodłączny i nie wynika jedynie z naszych ograniczonych zdolności pojmowania ogromnego obszaru przyrody. Wiedza o własnościach cząstek oraz przewidywanie zdarzeń lub ruchu mają wyłącznie charakter statystyczny. Niektórzy autorzy, między innymi Kenneth Miller ${ }^{6}$ i Robert John Russell, ${ }^{7}$ zauważają, że daje to okazję do mówienia o Bogu realizującym swoją opatrznościową wolę w sposób niemożliwy do wykrycia za pomocą naturalistycznych metod.

\section{Radioaktywność}

Radioaktywność zasługuje na szczególną uwagę. Wynika ona z kwantowego zachowania oddziaływania silnego, które wiąże nukleony. Tempo rozpadu radioaktywnego niestabilnych jąder można wyznaczyć z dużą dokładnością, ale

\footnotetext{
* (Przyp. rec.) Jest to uproszczenie: nie chodzi o wszystkie cechy cząstki. Funkcja falowa pozwala na obliczenie prawdopodobieństwa tego, że w rezultacie pomiaru uzyskamy określoną wartość mierzonej wielkości fizycznej. Ale dotyczy to obserwabli, czyli wielkości reprezentowanych w matematycznym formalizmie mechaniki kwantowej przez operatory hermitowskie. Obserwablami są na przykład położenie, pęd i energia, ale już nie masa spoczynkowa czy ładunek elek tryczny. Nie można zatem statystycznego charakteru kwantowo mechanicznych predykcji uogólniać na wszystkie cechy mikroobiektów. Zatem twierdzenie, że „wiedza na temat cząstki jest z natury statystyczna", zawiera tyleż prawdy, ile fałszu. 1999.

${ }^{6}$ Por. Kenneth R. Miller, Finding Darwin's God, Harper-Collins Publishers, New York

${ }^{7}$ Por. Robert J. Russell, „Special Providence and Genetic Mutation: A New Defense of Theistic Evolution”, w: Keith B. Miller (ed.), Perspectives on an Evolving Creation, Eerdmans, Grand Rapids 2003, s. 335-369.
} 
nawet $\mathrm{w}$ zasadzie nie da się przewidzieć momentu rozpadu jakiegoś konkretnego atomu. $Z$ powodu tej niepoznawalności radioaktywność pojedynczych atomów należy zaliczyć do zbioru $N_{n}$.

\section{Paradoks EPR}

Paradoks Einsteina-Podolsky’ego-Rosena był częścią Einsteinowskiej krytyki mechaniki kwantowej. ${ }^{8}$ Dwie splątane cząstki, które opisuje się za pomocą pojedynczej spójnej funkcji falowej, zachowują współzależne cechy ${ }^{*}$ nawet po znacznym oddaleniu się od siebie, dopóki spójność ta nie zostanie zerwana. Kiedy przeprowadza się pomiary dla tych cząstek, okazuje się, że są one nadal skorelowane. To „upiorne oddziaływanie na odległość”, jak prześmiewczo określił ten efekt Einstein, zostało później eksperymentalnie potwierdzone, jest jednak zupełnie niezrozumiałe. Wciąż pozostaje do ustalenia, do którego zbioru $-N_{n}$ czy $N_{p}$ — należy zaliczyć to zjawisko.

\section{Nieodróżnialność}

Pewne cechy cząstek są niepoznawalne ze względu na naturę cząstek elementarnych. Każdą cząstkę można scharakteryzować przy pomocy zbioru własności, takich jak spin, liczba barionowa, energia i tak dalej. Własności te są jednak wspólne wszystkim cząstkom. Jeżeli więc dwie cząstki posiadają te same cechy, to są nierozróżnialne. Niemożliwe jest odróżnienie cząstek elementarnych tego samego rodzaju. To samo odnosi się do molekuł i innych małych układów cząstek.

Możliwość odróżniania ich pojawia się tylko wtedy, gdy liczba stanów równowagi przewyższa liczebność populacji. Na przykład atom wodoru ma jeden stan podstawowy (choć o różnych orientacjach wektora momentu pędu), a liczba tych atomów we Wszechświecie przekracza $10^{50}$. Ich populacja jest więc dużo większa niż liczba stanów równowagi, wobec czego wszystkie te atomy są

\footnotetext{
${ }^{8}$ Por. Albert Einstein, Boris Podolsky, and Nathan Rosen, „Can Quantum Mechanical Description of Physical Reality Be Considered Complete?”, Physical Review 1935, vol. 47, s. 777.

* (Przyp. tłum.) Na przykład spin elektronów lub polaryzację fotonów.
} 
nieodróżnialne. Dla porównania każdy płatek śniegu zawiera około $10^{20}$ jednakowych cząsteczek wody, które mogą się konfigurować na tak wiele sposobów, że liczba możliwych stanów znacznie przewyższa całkowitą liczbę płatków śniegu, których tworzy się tylko około $10^{24} \mathrm{w}$ ciągu roku. Populacja płatków śniegu jest tak niewielka w porównaniu z liczbą możliwych stanów, że istnieje znikomo małe prawdopodobieństwo pojawienia się dwóch identycznych płatków.

Występowanie różnic między elementami jakiegoś zbioru możemy także opisać za pomocą pojęcia entropii, $S$, którą definiuje się jako $S=k \ln N$, gdzie $k$ oznacza stałą Boltzmanna równą $1,38 \times 10^{-23} \mathrm{~J} / \mathrm{K}$, a $N$ jest liczbą stanów równowagi. * Jednoznaczne rozróżnienie między elementami danej populacji jest możliwe tylko w sytuacji, gdy wartość entropii jest wysoka, a wielkość populacji stosunkowo niewielka.

O odrębności każdej substancji lub bytu nie decyduje zatem niepowtarzalność elementów składowych, lecz ich struktura oraz dynamika powiązań. Substancja może zostać zrekonstruowana, a byt wskrzeszony poprzez odtworzenie tej samej konfiguracji, bez konieczności użycia tych samych komponentów.

Odróżnialność cząstek elementarnych, atomów i molekuł należy oczywiście zaliczyć do zbioru $N_{n}$. Czy Bóg zna tożsamość każdej z nich? Możemy co najwyżej spekulować, jednak z naszej perspektywy odpowiedź na to pytanie nie ma większego znaczenia.

Wiek każdej substancji to czas, jaki upłynął od jej powstania. Jeśli żaden obserwator nie zarejestrował momentu, w którym się pojawiła, ani nie śledził jej historii, to o jej wieku można jedynie wnioskować na podstawie tempa zmiany jakiejś cechy. Żadna cząstka elementarna, pojedynczy atom lub molekuła w stanie podstawowym nie ma ani jednej cechy, która z upływem czasu ulega ukierunkowanej stopniowej zmianie. Tylko aglomeraty cząstek, dostatecznie duże, by posiadać rozpoznawalne, zmieniające się w czasie cechy, mogą mieć własności przydatne dla określenia wieku. Tylko Bóg zna wiek cząstek elementarnych, dla nas zaś taka informacja pozostaje częścią zbioru $N_{n}$.

\footnotetext{
* (Przyp. rec.) Ściślej mówiąc, $N$ jest prawdopodobieństwem termodynamicznym, czyli liczbą mikrostanów realizujących ten sam makrostan.
} 


\section{Kosmologia}

Zważywszy na ogrom przestrzeni i czasu, zdobyliśmy zadziwiająco dużą wiedzę o powstaniu i ewolucji Wszechświata. W ostatnich latach kosmologowie szczególnie efektywnie dowiadywali się, jak wiele kwestii jest jeszcze nieznanych. Obecnie wydaje się potwierdzone, że tylko 5\% masy Wszechświata można przypisać zwykłej materii. Kolejne $25 \%$ stanowi prawdopodobnie ciemna materia, a około $70 \%$ - ciemna energia. Ciemnej materii nie tylko nie jesteśmy $\mathrm{w}$ stanie zobaczyć, ale też nie jest zbudowana $\mathrm{z}$ żadnego ze znanych rodzajów cząstek. Jej pochodzenie pozostaje tajemnicą. Ciemna energia może odpowiadać stałej kosmologicznej, którą Einstein wprowadził do pierwotnej wersji ogólnej teorii względności (później się z tego wycofał). ${ }^{9}$ Do którego ze zbiorów $-N_{n}$ czy $N_{p}$ - powinniśmy więc zaliczyć ciemną materię i energię? Jeśli poznawalność definiuje się wyłącznie w kontekście znanych obecnie oddziaływań, cząstek i praw przyrody, to musimy odpowiedzieć, że do zbioru $N_{n}$. Naukowcy nadal żywią nadzieję, że uda im się odkryć nowe wymiary rzeczywistości, co pozwoliłoby uznać kwestię pochodzenia ciemnej materii i energii za poznawalną. Dwiema spośród dyskutowanych obecnie propozycji są pętlowa grawitacja kwantowa ${ }^{10}$ oraz M-teoria (obejmująca pięć rodzajów teorii strun). ${ }^{11}$ Pierwsza z nich opiera się na kwantyzacji zarówno przestrzeni, jak i czasu, podczas gdy podstawą drugiej jest siedem dodatkowych wymiarów przestrzennych, oprócz uznawanych dotąd czterech wymiarów czasoprzestrzeni. Jedno jest pewne powstania naszego Wszechświata i naszej planety nie można zrozumieć w ramach aktualnego „modelu standardowego”.

Powstanie i rozwój Wszechświata zależą głównie od wartości wielu stałych fizycznych, takich jak siła oddziaływań grawitacyjnych i jądrowych, stała struktury subtelnej, prędkość światła i tak dalej. Mimo że jesteśmy w stanie mierzyć

\footnotetext{
${ }^{9}$ Por. np. Robert P. KIRShner, The Extravagant Universe: Exploding Stars, Dark Energy, and the Accelerating Cosmos, Princeton University Press 2002.

${ }^{10}$ Por. Lee Smolin, „Atomy czasu i przestrzeni”, Świat Nauki 2004, nr 2 (150), s. 52-61.

${ }^{11}$ Por. Brian Greene, Piękno Wszechświata. Superstruny, ukryte wymiary i poszukiwanie teorii ostatecznej, przeł. Bogumił Bieniok i Ewa L. Łokas, Na Ścieżkach Nauki, Prószyński i S-ka, Warszawa 2001.
} 
te parametry, zupełnie nie mamy pojęcia, dlaczego mają one takie a nie inne wartości. Bardzo niewielkie zmiany któregokolwiek z nich uniemożliwiłyby ukształtowanie się we Wszechświecie planety przyjaznej dla życia takiego, jakie znamy. Na tej podstawie sformułowano zasadę antropiczną, według której to projektant musiał dostroić owe stałe w sposób pozwalający na zaistnienie ludzkiego życia. ${ }^{12}$ Nie wiemy, czy pewnego dnia zostanie sformułowana „teoria wszystkiego”, z której będzie można wyprowadzić wartości stałych fizycznych. Na razie nie wiadomo, dlaczego mają one właśnie takie wartości.

\section{Biologia}

Powstanie życia, gatunków i pochodzenie umysłu to trzy główne obszary biologii, które nadal stanowią niewiadome. Darwinowska teoria ewolucji jest owocnym (chociaż wciąż niekompletnym co do szczegółów) wytłumaczeniem powstawania gatunków, ale nie istnieją powszechnie akceptowane wyjaśnienia dotyczące pochodzenia życia oraz umysłu. Większość dzisiejszych teorii inteligentnego projektu opiera się na twierdzeniach, że naturalistyczne powstanie życia i umysłu jest wysoce nieprawdopodobne, a zatem problem ten należy zaliczyć do zbioru $N_{n}$. Bardziej prawdopodobne jest według nich bezpośrednie działanie sprawcze inteligentnego projektanta. Według Behe'ego obserwowana w biologii molekularnej nieredukowalna złożoność, na przykład hemoglobiny *

\footnotetext{
${ }^{12}$ Por. W. Jim Neidhart, „The Anthropic Principle: A Religious Response”, Journal of the American Scientific Affiliation 1984, vol. 36, s. 201-207.

* (Przyp. thum.) Michael Behe w innym kontekście zaprzecza, jakoby używał pojęcia nieredukowalnej złożoności w odniesieniu do hemoglobiny: „Ale te kilka hemoglobin, które Futuyma nazywa «'nieredukowalnie złożonym' systemem białek oddechowych», w rzeczywistości nie stanowi układu nieredukowalnie złożonego w moim rozumieniu tego terminu. [...] nigdy nie używałem tego terminu w połączeniu z hemoglobiną — wręcz przeciwnie” (Michael J. BeHE, „Filozoficzne zarzuty stawiane hipotezie inteligentnego projektu: odpowiedź na krytykę", przeł. Dariusz Sagan, w: Dariusz SAGAN, Spór o nieredukowalną złożoność układów biochemicznych, Biblioteka Filozoficznych Aspektów Genezy, t. 5, Wydawnictwo MEGAS, Warszawa 2008, s. 224 [217232], http://www.nauka-a-religia.uz.zgora.pl/index.php?action=tekst\&id=150 [16.11.2012]). Oto inna jego wypowiedź na ten temat: „Chociaż hemoglobinę można uznać za system złożony ze współdziałających części, jego oddziaływanie właściwie nie jest inne niż to, które zapewniają po jedyncze składniki systemu" (Michael J. Behe, Czarna skrzynka Darwina. Biochemiczne wyzwanie dla ewolucjonizmu, przeł. Dariusz Sagan, Biblioteka Filozoficznych Aspektów Genezy, t. 4, Wydawnictwo MEGAS, Warszawa 2008, s. 181).
} 
lub wici, uniemożliwia poznanie ich rozwoju w ramach teorii ewolucji. ${ }^{13}$ Miller ${ }^{14}$ przedstawia jednak możliwe scenariusze ewolucji tych układów. Mills ${ }^{15}$ zarzuca Millerowi, że nie wykazał, iż te ścieżki ewolucyjne rzeczywiście zostały wykorzystane. Argument Millsa nie jest trafny. Skoro można opisać wiarygodne ścieżki utworzenia się tych struktur, to nawet jeśli nie uda się potwierdzić, że została wskazana rzeczywista droga ich rozwoju, nie będzie stanowiło to podstawy dla przyznania racji Behe'emu i Millsowi, że jest ona niepoznawalna. Dopóki jakiś element nie stanie się częścią zbioru $W$, nie można mieć pewności, czy znajdował się w podzbiorze $N_{p}$ czy $N_{n}$. Aby wykazać, że dane zjawisko należy do podzbioru $N_{n}$, potrzeba danych świadczących o tym, że poznanie go jest niemożliwe, a nie tylko, że aktualne wyjaśnienia są nieadekwatne.

Według Dembskiego teoria informacji dowodzi, że umysł oraz złożone struktury, będące podstawą życia, nie mogły powstać w naturalny sposób. ${ }^{16}$ Analizując pojęcia złożonej specyficzności i specyficznej złożoności, argumentuje on, że przypadkowe procesy nie potrafią wytworzyć układów charakteryzujących się wyspecyfikowaną złożonością. Ruse zwraca uwagę, że jest to fałszywy dylemat, a tym samym twierdzenie, że geneza życia jest niepoznawalna, nie ma przekonujących podstaw. ${ }^{17}$

Często również podnosi się argumenty z nieprawdopodobieństwa, uparcie twierdząc, że powstanie życia i umysłu musi należeć do zbioru $N_{n}$, a nie $N_{p} \cdot{ }^{18}$ $\mathrm{Z}$ pewnością da się wykazać, że prawdopodobieństwo niektórych zdarzeń jest na tyle niskie, by można było uznać, że nigdy nie zajdą one w czasie istnienia Wszechświata. Jednakże z tego rodzaju wyliczeń w odniesieniu do przeszłych

\footnotetext{
${ }^{13}$ Por. Behe, Czarna skrzynka Darwina....

${ }^{14}$ Por. Miller, Finding Darwin's God..., s. 129-164.

${ }^{15}$ Por. Gordon C. Mills, „In Defense of Intelligent Design”, Perspectives on Science and Christian Faith 2002, vol. 54, s. 260-263.

${ }^{16}$ Por. William A. Dembsкi, „Intelligent Design as a Theory of Information”, Perspectives on Science and Christian Faith 1997, vol. 49, s. 180-190.

${ }^{17}$ Por. Michael Ruse, Can a Darwinian be a Christian?, Cambridge University Press, Cambridge 2001, s. 120-122.

${ }^{18}$ Por. Arthur E. Wilder-Smith, Man's Destiny, Man's Origins, Harold Shaw Publishers, Wheaton, Illinois 1968, s. 57-70.
} 
zdarzeń wynika tylko, że przy obliczaniu prawdopodobieństwa rozpatrzono zapewne niewłaściwe procesy fizyczne lub przyjęto błędne założenia, natomiast nie można na ich podstawie wyciągnąć wniosku, że wyjaśnienie danego zjawiska należy do zbioru $N_{n}$.

Można rozważać jeszcze inne dziedziny, jak choćby twierdzenie Gödla lub pewne obszary matematyki, w których poznanie okazuje się z natury ograniczone. Luki w wiedzy istnieją, nie tylko te spowodowane niedoskonałością naszej percepcji, ale również takie, które społeczność naukowa uznaje za niepoznawalne w zasadzie. Większość spośród tych, jakie wyżej omówiono, szczególnie pierwsze cztery kategorie, odnosi się do opisowych własności materii, a nie czynników przyczynowych. Chociaż Bóg może (ale nie musi) posiadać nadnaturalną wiedzę o takich cechach, to istnienia Boskiego Stwórcy zwykle nie uzasadnia się na podstawie naszej niezdolności do wypełnienia owych luk. Nie ma żadnego poważnego powodu, by wierzyć, że musi istnieć byt, który taką wiedzę posiada. W kosmologii i biologii oraz do pewnego stopnia w przypadku nieoznaczoności kwantowej luki przeważnie dotyczą wyjaśnień zjawisk lub wyjaśniania, dlaczego pewne cechy mają określoną wartość. To właśnie te luki najczęściej przedstawia się jako świadectwa istnienia Stwórcy. Nie ma jednakże żadnej istotnej przyczyny, by uznać, że konieczne jest ich wypełnienie, czy to w naturalistyczny, czy inny sposób.

Błędność argumentów typu „Bóg w lukach wiedzy” nie polega na tym, że owe luki pewnego dnia zostaną wypełnione, ${ }^{19}$ lecz że nie wskazują one na Boga Stwórcę. Najmocniejszym argumentem na rzecz istnienia Boga jest w rzeczywistości taki argument z projektu, którego podstawą nie jest zbiór $N_{n}$, lecz zbiór $W .{ }^{20}$ Zagadka, dlaczego Wszechświat jest w ogóle pojmowalny, może być tą ostateczną luką, która prowadzi do Boga. Tego rodzaju argument nie jest logicznym, niepodważalnym dowodem naukowym, lecz manifestacją dzieła Bożego dla tych, którzy „wierzą, że On istnieje i że nagradza tych, którzy go szu-

\footnotetext{
${ }^{19} \mathrm{Na}$ przykład Snoke sprzeciwia się stanowisku krytycznemu względem koncepcji „Boga w lukach wiedzy”, ponieważ zakłada ono, ,że stały postęp nauki wyjaśnia i rozwiązuje wszystko" (David Snoke, „In Favor of God-of-the-Gaps Reasoning”, Perspectives on Science and Christian Faith 2001, vol. 53, s. 152-158).

${ }^{20}$ Por. np. Howard J. VAN TILL, „Creation: Intelligently Designed or Optimally Gifted”, Theology Today 1998, vol. 55, s. 344-364.
} 
kają". ${ }^{21}$ Naturalistyczna wiedza prowadzi do wniosku o istnieniu nadnaturalnego Stwórcy nie z powodu jej nieprzezwyciężalnych ograniczeń, ale ze względu na samą możliwość jej zdobywania. Wyjątkowe piękno i elegancja tej części Wszechświata, którą potrafimy wyjaśnić, czy to na podstawie zwykłej obserwacji, czy równań Maxwella albo Schrödingera, dobitnie ukazują potęgę i chwałę Boga wszystkim ludziom, nie tylko specjalistom, którzy potrafią rozpoznawać elementy zbioru $N_{n}$. „Bo niewidzialna jego istota, to jest wiekuista jego moc i bóstwo, mogą być od stworzenia świata oglądane w dziełach i poznane umysłem, tak iż nic nie mają na swoją obronę". ${ }^{22}$

Randy Isaac

\section{From Gaps to God}

\section{Summary}

Arguments for the existence of God that are based on design often specify an aspect of our natural world that cannot be explained by our current understanding of the laws of nature. Such a gap of knowledge is construed as evidence for the existence of a supernatural being. Critics of this approach label these arguments as „God-of-the-gaps” fallacies that diminish the case for a Creator God as the gaps are filled in with increasing knowledge. Confident that all such gaps will someday be filled via the scientific method, many people reject design arguments for God. However, gaps of knowledge do exist in nature and the scientific community acknowledges that many cannot be filled, even in principle. This article surveys various types of gaps and considers their role in an argument for God.

Keywords: God-of-the-gaps argument, design argument, naturalistic knowledge, unknowability in principle, practical unknowabililty.

Slowa kluczowe: argument typu Bóg w lukach wiedzy, argument z projektu, wiedza naturalistyczna, niepoznawalność zasadnicza, niepoznawalność praktyczna.

\footnotetext{
${ }^{21}$ Hbr 11:6b (BW).

${ }^{22} \mathrm{Rz}$ 1:20 (BW).
} 